\title{
Enhanced magnetic properties of FePt nanoparticles codeposited on Ag nanoislands
}

\author{
L. Castaldi, ${ }^{1,2, a)}$ K. Giannakopoulos, ${ }^{1}$ A. Travlos, ${ }^{1}$ N. Boukos, ${ }^{1}$ D. Niarchos, ${ }^{1}$ S. Boukari, ${ }^{3}$ \\ and E. Beaurepaire \\ ${ }^{1}$ IMS, NCSR “Demokritos,” Agia Paraskevi, Attiki 15310, Greece \\ ${ }^{2}$ Laboratory for Nanoscale Materials Science, Empa, Überlandstr. 129, CH-8600 Dübendorf, Switzerland \\ ${ }^{3}$ IPCMS, UMR 7504 CNRS-ULP, 23 rue du Loess, BP43, F-67034 Strasbourg Cedex 2, France
}

(Received 24 November 2008; accepted 10 March 2009; published online 6 May 2009)

\begin{abstract}
$\mathrm{Ag}$ nanoislands have been used as nucleation sites for FePt nanoparticles when deposited on $\mathrm{SiO}_{2}$ surfaces by electron beam evaporation. We demonstrate that it is possible to nucleate $\mathrm{FePt}$ nanoparticles on predeposited Ag clusters and that this results in a significant improvement of the hard magnetic Ag/FePt nanoparticles' properties. We find that, besides the usual annealing treatments, a simple predeposition of Ag nanoclusters promotes the formation of the FePt $L 1_{0}$ phase at larger FePt nominal thicknesses $\left(f_{\mathrm{FePt}}\right)$. All the nanoparticles studied are ferromagnetic, except for those FePt samples deposited with lower nominal thicknesses $\left(f_{\mathrm{FePt}} \sim 1.8 \mathrm{~nm}\right)$, which are superparamagnetic. The presence of $\mathrm{Ag}$ seeds promotes the $A 1 / L 1_{0}$ transition, which results in a remarkable enhancement of the coercivity $\left(H_{c}\right)$ for both the as-deposited and the annealed samples. Maximum $H_{c}$ of 8.9 and $9.4 \mathrm{kOe}$ are obtained for the $\mathrm{Ag} / \mathrm{FePt}$ nanoparticles with $f_{\mathrm{FePt}} \sim 1.8$ and 3.5 $\mathrm{nm}$, respectively. Our results are a strong indication that the nucleation of the FePt nanoparticles on Ag nanoclusters can promote significant magnetic hardening of the FePt nanoparticles by easing the transition from the disordered to the ordered phase. (C) 2009 American Institute of Physics.
\end{abstract}

[DOI: $10.1063 / 1.3116558$ ]

\section{INTRODUCTION}

In recent years, significant scientific and technological effort has been devoted to research on FePt nanoparticles for high density recording media, ${ }^{1}$ high performance nanocomposite magnets, ${ }^{1}$ and multifunctional systems for integrated circuitry. ${ }^{2,3}$ The community's interest in this material lies in the magnitude of the anisotropy constant of the $L 1_{0}$ ordered phase, ${ }^{1}$ which enables us to prevent the formation of the superparamagnetic state at room temperature for particles as small as $3 \mathrm{~nm}$ (in diameter). ${ }^{4,5}$

The $L 1_{0}$ ordered phase of the FePt bulk alloy is thermodynamically more stable ${ }^{1}$ than the $A 1$ disordered phase, up to a critical temperature $T_{c} \sim 1300{ }^{\circ} \mathrm{C}$. The growth of $\mathrm{FePt}$ nanostructures at relatively low substrate temperature $\left(T_{s}\right)$ results in the formation of the metastable $A 1$ structure. ${ }^{6,7}$ Thus, to obtain FePt nanoislands of the $L 1_{0}$ phase, it is necessary to use high $T_{s}$ (Ref. 6) or thermal annealing. ${ }^{7,8}$ More recently, introducing immiscible metallic additives, such as $\mathrm{Au}, \mathrm{Cu}$, and $\mathrm{Ag},{ }^{9-14}$ has been shown to promote the ordering transformation at lower $T_{s}$, by providing a decrease in the activation energy. ${ }^{10}$ Until now, this concept has been demonstrated only on nanoparticles $9,11,12,14$ synthesized with chemical methods on thin films ${ }^{10}$ and on multilayer structures. ${ }^{14}$ While thin film deposition methods are ubiquitous in a wide range of nanomaterial technologies, mainly because of their simplicity and flexibility, but also because of their high yields in industrial processes, there is no evidence in the literature of free standing $\mathrm{Ag} / \mathrm{FePt}$ nanoparticles prepared using such techniques. This is due to the fact that the formation

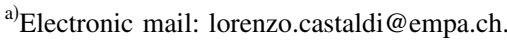

of nanoparticles by deposition methods is possible only within a narrow range of growth parameters. ${ }^{15}$ However, although the deposition of metals in a subpercolation regime is a complex process, in principle, Ag nanoclusters grown before the deposition of FePt could act as nucleation sites for the subsequent deposition of FePt nanoparticles.

The aim of the present study is to investigate the effect of $\mathrm{Ag}$ nanoclusters (predeposited on $\mathrm{SiO}_{2} / \mathrm{Si}$ substrates by e-gun evaporation) on the structural, morphological, and magnetic properties of $\mathrm{Ag} / \mathrm{FePt}$ nanoparticles formed during a second step of Fe and Pt codeposition. This study compares $\mathrm{Ag} / \mathrm{FePt}$ with FePt nanoparticles, where the $\mathrm{Ag}$ deposition step has been omitted and codeposited on $\mathrm{Si} / \mathrm{SiO}_{2}$ wafers under identical conditions.

\section{EXPERIMENTAL}

$\mathrm{Ag}, \mathrm{FePt}$, and $\mathrm{Ag} / \mathrm{FePt}$ nanoparticles were deposited by electron beam coevaporation at a base pressure of 2 $\times 10^{-7}$ mbar with a substrate temperature $\left(T_{s}\right)$ of $\sim 500{ }^{\circ} \mathrm{C}$. ${ }^{15}$ All specimens were grown on thermally oxidized silicon (100) substrates with $\mathrm{a} \mathrm{SiO}_{2}$ amorphous layer of $\sim 100 \mathrm{~nm}$ on top. The FePt were prepared by codeposition of Fe and $\mathrm{Pt}$, while the $\mathrm{Ag} / \mathrm{FePt}$ nanoparticles were prepared in two steps: the initial deposition of $\mathrm{Ag}$ particles and the subsequent codeposition of $\mathrm{Fe}$ and $\mathrm{Pt}$, under identical conditions. In all depositions the partial deposition rate was $\sim 0.030 \mathrm{~nm} / \mathrm{s}$ when depositing Fe and $0.033 \mathrm{~nm} / \mathrm{s}$ when depositing $\mathrm{Ag}$ or $\mathrm{Pt}$. The $\mathrm{Fe}$ and $\mathrm{Pt}$ deposition rates led to an approximate atomic ratio $\mathrm{Fe}: \mathrm{Pt} \sim 1$. The deposition rate for each material was controlled by an independent quartz crystal thickness monitor. 
TABLE I. Main growth parameters ( $f$ is the total thickness and $f_{\mathrm{FePt}}$ is the FePt nominal thickness) and the most relevant morphological $\left(D_{p}\right.$ is the mean particle size and $\delta$ is the particle density) and magnetic $\left(H_{c}\right.$ is the perpendicular coercivity) properties of the $\mathrm{FePt}$ and $\mathrm{Ag} / \mathrm{FePt}$ nanoparticles.

\begin{tabular}{|c|c|c|c|c|c|c|}
\hline & ID sample & $\begin{array}{c}f \\
(\mathrm{~nm})\end{array}$ & $\begin{array}{l}f_{\mathrm{FePt}} \\
(\mathrm{nm})\end{array}$ & $\begin{array}{c}D_{p} \\
(\mathrm{~nm})\end{array}$ & $\begin{array}{c}\delta \\
\left(\times 10^{11} / \mathrm{cm}^{2}\right)\end{array}$ & $\begin{array}{c}H_{c} \\
(\mathrm{kOe})\end{array}$ \\
\hline $\mathrm{Ag}$ & $\cdots$ & 1.5 & $\ldots$ & 7.0 & 5 & $\ldots$ \\
\hline \multirow[t]{4}{*}{$\mathrm{FePt}$} & A & 3.5 & 3.5 & 6.9 & 8.8 & 1.9 \\
\hline & $\mathrm{B}^{\mathrm{a}}$ & 3.5 & 3.5 & 8.1 & 8.3 & 7.7 \\
\hline & $\mathrm{C}$ & 1.8 & 1.8 & 5.4 & 18.8 & 0 \\
\hline & $\mathrm{D}^{\mathrm{a}}$ & 1.8 & 1.8 & 5.4 & 13.1 & 0.1 \\
\hline \multirow[t]{4}{*}{$\mathrm{Ag} / \mathrm{FePt}$} & $\mathrm{E}$ & 5 & 3.5 & 9.1 & 5.8 & 2.6 \\
\hline & $\mathrm{F}^{\mathrm{a}}$ & 5 & 3.5 & 8.4 & 3.6 & 9.4 \\
\hline & G & 3.3 & 1.8 & 5.5 & 12.2 & 3.1 \\
\hline & $\mathrm{H}^{\mathrm{a}}$ & 3.3 & 1.8 & 5.6 & 7.4 & 8.9 \\
\hline
\end{tabular}

${ }^{\mathrm{a}}$ Samples annealed at $700{ }^{\circ} \mathrm{C}$ in situ 5 min. immediately after deposition.

In Table I, we define samples $\mathrm{A}-\mathrm{H}$ according to their deposition and annealing conditions and show the nominal thickness of the layer $f$, the mean crystallite size $D_{\text {cryst }}$, the mean particle diameter $D_{p}$, the particle density $\delta$, and the coercivity $H_{c}$ measured along the perpendicular direction with respect to the substrate plane. Selected samples were annealed at $700{ }^{\circ} \mathrm{C}$ for $5 \mathrm{~min}$ in vacuum, immediately after their deposition.

The structural and morphological properties of the samples were analyzed by $\mathrm{x}$-ray diffraction (XRD) and transmission electron microscopy (TEM). The X-ray diffractometry was performed with $\mathrm{Cu} K \alpha$ radiation; the mean crystallite size $D_{\text {cryst }}$ was estimated by line broadening analysis on nonoverlapping peaks, using the Scherrer formula. TEM was performed with a Philips CM20. This instrument has high resolution capabilities and is equipped with an energy dispersion $\mathrm{X}$-ray spectrometer for quantitative chemical characterization and a Gatan Imaging Filter for the acquisition of electron energy loss spectra and energy filtered TEM (EFTEM) images. The magnetic properties of the FePt nanoislands were measured using a magneto-optical Kerr effect magnetometer at room temperature (a maximum field of $22 \mathrm{kOe}$ ). Corrections for self-demagnetization, to determine the exact internal field of the samples during the magnetic measurements, were not performed.

\section{RESULTS AND DISCUSSION}

The crystallographic characterization of the $\mathrm{Ag} / \mathrm{FePt}$ nanoparticles described in this study deals with two challenges: (i) the so-called "nanostructure problem," 16 i.e., the difficulty to characterize the crystallographic structure of material within the 1-10 nm scale, and (ii) the small quantity of material detectable by XRD, TEM, or other techniques. For this reason, since the nominal thickness of the FePt nanoparticles described in this study is within the $1.8-3.5 \mathrm{~nm}$ range, TEM or XRD techniques cannot provide a complete and conclusive information on their crystallographic structure. For this reason, it is necessary to combine complementary methods, i.e., XRD, TEM, and magnetometry, to infer the collective crystallographic structure of the FePt and $\mathrm{Ag} / \mathrm{FePt}$ nanoislands.

\section{A. Morphological properties}

It is well known that during the first deposition stage of metals on amorphous oxides, isolated islands form according to the Wolmer-Weber growth mechanism. ${ }^{17}$ During the initial stage of the coarsening process, there are small and large nanoislands and the particle size distribution (PSD) is bimodal. The equilibrium density of the nanoparticles $\left(\delta_{\mathrm{eq}}\right)$ is achieved as a consequence of the higher bidimensional evaporation rate of the smaller clusters than the larger ones ${ }^{18}$ (Ostwald ripening). Consequently, at equilibrium, the smallest clusters disappear and the PSD becomes monomodal. The radius of curvature $(R)$ and $\delta_{\mathrm{eq}}$ of metallic nanoparticles, grown according to the Wolmer-Weber mechanism, depends on the temperature $T_{s}$ and the surface energy of the nanoparticles $\left(\gamma_{n}\right)$. Their relationship is described by the GibbsThomson equation: ${ }^{18}$

$$
\delta_{\text {eq }}=\delta_{\infty} \exp \left(\frac{\gamma_{n}}{\rho K_{B} T_{s} R}\right),
$$

where $\delta_{\infty}$ is the density of particles of infinite size, $\rho$ is the density of the material $\left(\rho \sim 10.5\right.$ and $15.0 \mathrm{~g} / \mathrm{cm}^{3}$ for $\mathrm{Ag}$ and $\mathrm{FePt}$, respectively ${ }^{19}$ ), $K_{B}$ is the Boltzmann constant, and $\gamma_{n}$ is the surface energy of a nanoparticle $\left[1.2\right.$ and $17.2 \mathrm{~J} / \mathrm{m}^{2}$ for $\mathrm{Ag}$ (Ref. 20) and FePt, ${ }^{15}$ respectively]. As a consequence, the island density $\delta$ and the curvature $R$ of different materials, deposited under the same growth conditions, depend on the $\gamma_{n} / \rho$ ratio. Ag and FePt exhibit $\gamma_{n} / \rho$ ratios of 0.11 and 1.15, respectively. Consequently, the growth of the FePt alloy nanoparticles would lead to a larger $\delta$ when compared to the nanoisland density of the silver nanoparticles, with the same nominal thickness $f$. The growth of $\mathrm{Ag}$ at $500{ }^{\circ} \mathrm{C}$ with a nominal thickness of $1.5 \mathrm{~nm}$ on $\mathrm{SiO}_{2}$ results in the formation of droplike nanoparticles, as can be seen in the in-plane TEM images shown in Fig. 1(a), with a monomodal PSD and a mean particle size $D_{p} \sim 7 \mathrm{~nm}$ [see Fig. 1(b) and Table I]. Figure 2 shows a comparison of in-plane TEM images of nanoparticles grown without $\mathrm{Ag}$ [Figs. 2(a)-2(d), FePt] and after the deposition of the silver clusters [Figs. 2(e)-2(h), $\mathrm{Ag} / \mathrm{FePt}$. All the as-deposited FePt samples [Figs. 2(a) and 2(c) ] consist of elongated particles, suggesting that a droplet/ coalescence transition ${ }^{21,22}$ has occurred, while their PSDs' are bimodal and monomodal [empty squares in Figs. 3(a) 

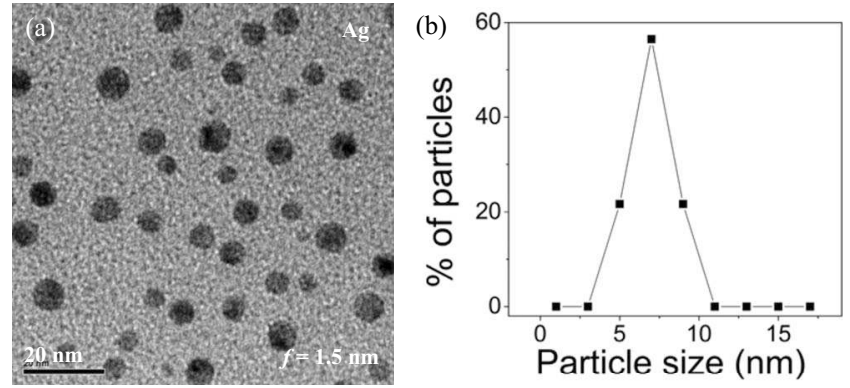

FIG. 1. (a) In-plane bright field TEM image and (b) PSD of the Ag nanoparticles.

and 3(b), respectively]. Interestingly, although the nominal thickness of $\mathrm{C}$ samples $(\mathrm{FePt})$ is just 1.2 times higher than in our pure $\mathrm{Ag}$ particles, their nanoisland density is more than three times larger (Table I). As mentioned above, this is consistent with the higher $\gamma_{n} / \rho$ ratio of FePt than $\mathrm{Ag}$ particles, which leads to larger $\delta$.

The postdeposition annealing at $700{ }^{\circ} \mathrm{C}$ for $5 \mathrm{~min}$ led to a decrease in the island density [Figs. 2(b) and 2(d), Table I] and an increase in the interparticle distance for both specimens ( $\mathrm{B}$ and $\mathrm{D}$ samples) as a consequence of the thickening of the nanoparticles ${ }^{17}$ and the Ostwald ripening. ${ }^{18}$ Despite the thermal annealing, the PSD of B samples is bimodal [full squares in Fig. 3(a)] suggesting, as mentioned above, that the nanoparticles are not in their equilibrium distribution. Conversely, the postannealing effect on the PSD of the FePt with $f \sim 1.8 \mathrm{~nm}$ [full squares in Fig. 3(a)] results in a sharpening of the monomodal PSD. Although the thermal annealing usually leads to an increase in the mean nanoisland size, as occurred for the nanoparticles with $f \sim 3.5 \mathrm{~nm}$, this trend can be counterbalanced by the thickening of the islands ${ }^{17}$ as observed in the D samples.

The predeposition of $\mathrm{Ag}$ seeds results in an increase in $D_{p}$ and a decrease in $\delta$ in the $\mathrm{Ag} / \mathrm{FePt}$ samples with $f_{\mathrm{FePt}}$ $\sim 3.5$ and $1.8 \mathrm{~nm}$, as can be seen in Table I and Figs. 2(e) $-2(\mathrm{~h})$. This is due to the larger total thickness, $f \sim 5.0$ and $3.3 \mathrm{~nm}$, respectively. The PSD of the Ag/FePt nanoparticles is broader than the FePt samples.
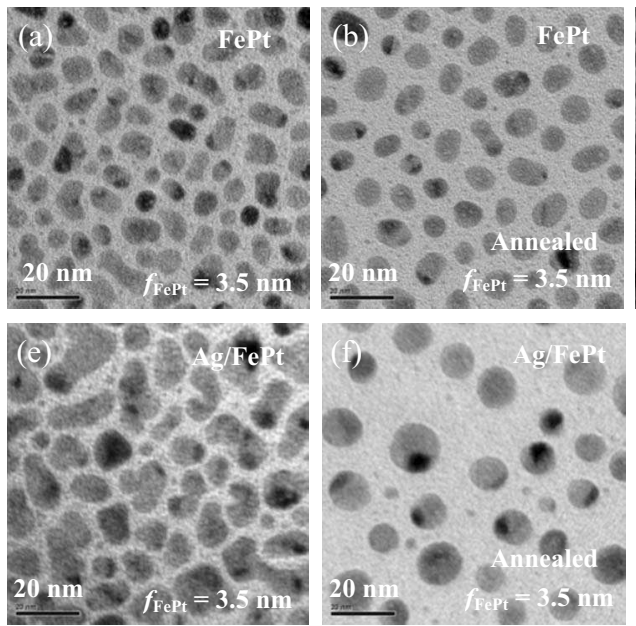

\section{B. Structural properties}

The XRD patterns obtained for the Ag nanoparticles (not shown here) exhibit no evidence of $\mathrm{Ag}$ peaks due to the low diffracting volume of the deposited material. Figure 4 shows the XRD patterns of the as-deposited and annealed FePt and $\mathrm{Ag} / \mathrm{FePt}$ samples, with $f_{\mathrm{FePt}} \sim 3.5 \mathrm{~nm}$ (A, B, E, and $\mathrm{F}$ samples). The diffraction peaks are very broad due to the small crystallite size (different from $D_{p}$ ). According to previous studies, ${ }^{15}$ the position of the diffraction peak of $\mathrm{FePt}$ nanoparticles has to be attributed to their crystallographic structure rather than other effects such as stress. Comparing the observed peak position with the (111) $A 1$ and $L 1_{0}$ diffraction lines, it is clear that the as-deposited FePt nanoparticles (A samples) have the $A 1$ structure mainly, while their annealing shifts the peak toward the (111) $L 1_{0}$ line (B samples). The (111) peak of the as-deposited $\mathrm{Ag} / \mathrm{FePt}$ nanoparticles (E samples) encompasses both the $A 1$ and the $L 1_{0}$ lines indicating the presence of both phases. Their subsequent annealing (F samples) leads to a shift of the diffraction peak toward the $L 1_{0}$ line, i.e., a significant volume fraction of the nanoparticles undergoes the $A 1 / L 1_{0}$ transition.

Figure 5 shows the XRD patterns of the as-deposited and annealed $\mathrm{FePt}$ and $\mathrm{Ag} / \mathrm{FePt}$ samples, with $f_{\mathrm{FePt}} \sim 1.8 \mathrm{~nm}(\mathrm{C}$, $\mathrm{D}, \mathrm{G}$, and $\mathrm{H}$ samples). Both the as-deposited and annealed FePt nanoparticles ( $\mathrm{C}$ and $\mathrm{D}$ samples) exhibit a large volume fraction of $A 1$ phase, inferred from the experimental peak position's coincidence with the $A 1$ (111) diffraction line. It is not clear to what extent the as-deposited $\mathrm{Ag} / \mathrm{FePt}$ nanoparticles (G samples) exhibit the $L 1_{0}$ ordered structure, while the annealed $\mathrm{Ag} / \mathrm{FePt}$ nanoparticles (H samples) do show the $L 1_{0}$ structure. These results are a strong indication that the addition of $\mathrm{Ag}$ favors the $A 1 / L 1_{0}$ phase transition. Since there is no evidence of $\mathrm{Ag}$ diffraction peaks even for pure $\mathrm{Ag}$ nanoparticles, it is not clear if the order/disorder transition in the FePt nanoparticles is due to the metastable incorporation of $\mathrm{Ag}$ in the $\mathrm{FePt},{ }^{7,14}$ which favors the kinetic ordering of the Fe and Pt during the Ag segregation and vacancy formation or to the local strain resulting from the Ag segregated at the boundary of the FePt nanoparticles. ${ }^{8}$ In order to elucidate
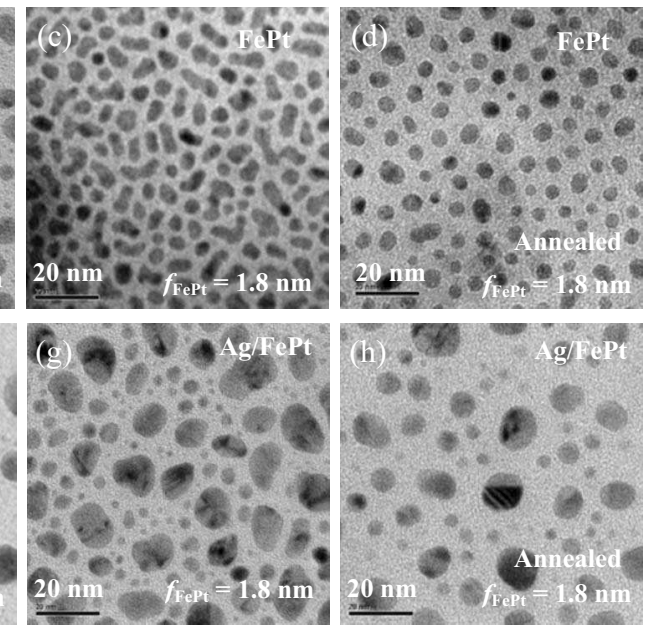

FIG. 2. In-plane bright field TEM image for (a) A samples, (b) B samples, (c) C samples, (d) D samples, (e) E samples, (f) F samples, (g) G samples, and (h) $\mathrm{H}$ samples. 


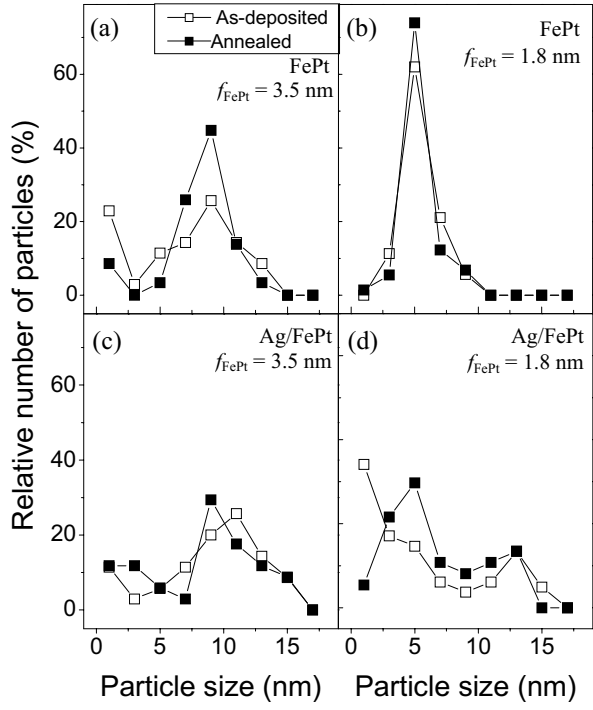

FIG. 3. PSDs for (a) A and B, (b) C and D, (c) E and F, and (d) G and H samples. The empty and full squares represent the as-deposited and annealed samples, respectively.

this, compositional maps were obtained by EFTEM analysis on selected specimens. For this purpose, we used the Fe $L_{3,2}$ and $\operatorname{Ag} L_{3,2}$ electron energy loss spectroscopy peaks in order to apply the three window method ${ }^{23}$ for the acquisition of the $\mathrm{Fe}$ and Ag EFTEM images, respectively. As can be seen in Fig. 6, the in-plane bright field TEM image of $\mathrm{F}$ samples [Fig. 6(b)] overlaps to a great extent with the $\mathrm{Ag}$ and $\mathrm{Fe}$ maps [Figs. 6(a)-6(c)], something which becomes more visible in larger particles. This is a strong indication that (at least for the larger particles) is possible to grow FePt on $\mathrm{Ag}$ nanoclusters and form $\mathrm{Ag} / \mathrm{FePt}$ free standing nanoparticles using a simple thin film deposition technique.

It is well known that the self-diffusion activation energy of atoms in metals or alloys is related to the strength of their bonding ${ }^{24,25}$ and, thus, to their surface energy. ${ }^{26}$ Therefore, the reduction in surface energy promoted by the presence of

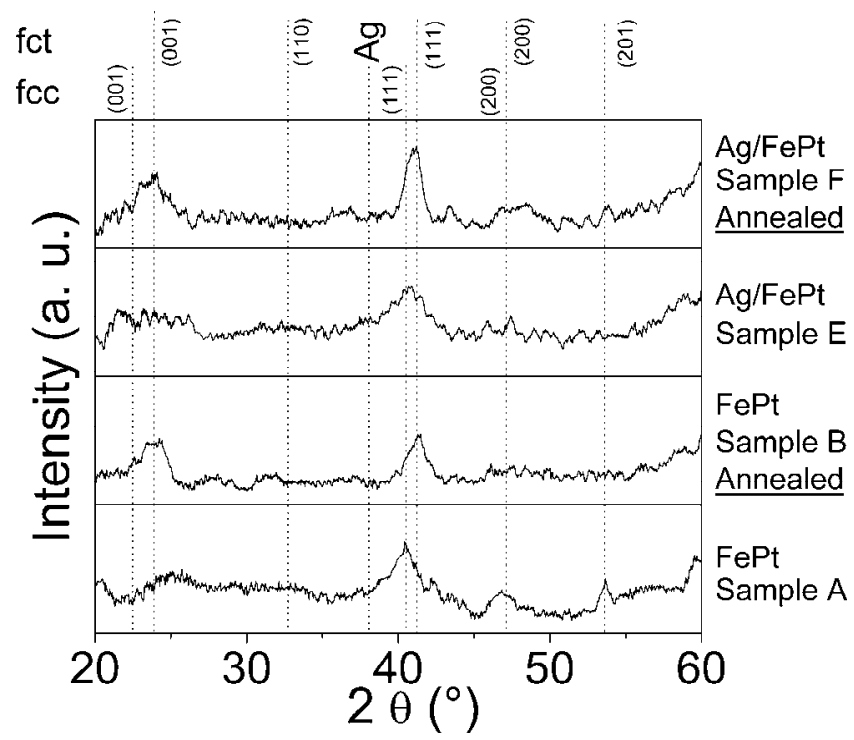

FIG. 4. XRD patterns of the FePt (A and B samples) and $\mathrm{Ag} / \mathrm{FePt}$ (E and $\mathrm{F}$ samples) nanoparticles with $f_{\mathrm{FePt}}=3.5 \mathrm{~nm}$.

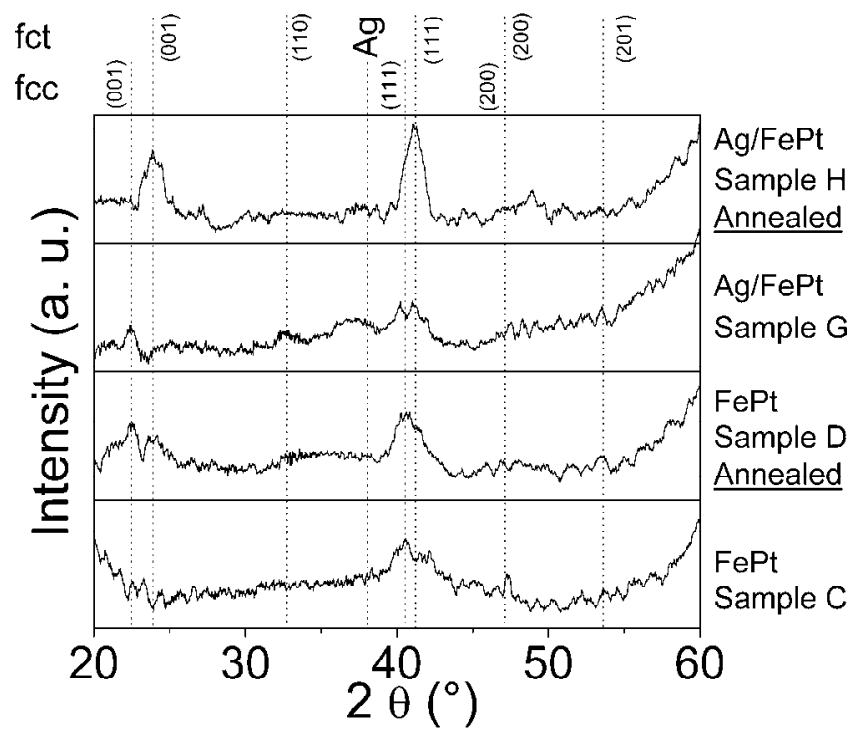

FIG. 5. XRD patterns of the FePt (C and D samples) and $\mathrm{Ag} / \mathrm{FePt}(\mathrm{C}$ and $\mathrm{H}$ samples) nanoparticles with $f_{\mathrm{FePt}}=1.8 \mathrm{~nm}$.

a surfactant in nanoparticles, such as $\mathrm{Ag}$ on FePt, can lead to higher mobility of the atoms and thus explain the increase in their kinetic ordering. This diffusion enhancement is also consistent with the increased grain growth ${ }^{12}$ and the kinetics of the $A 1 / L 1_{0}$ transition, ${ }^{10}$ observed in FePt nanoparticles, promoted by the addition of $\mathrm{Ag}$ in our samples.

\section{Magnetic properties}

Figure 7 shows the magnetization curves, measured along the perpendicular direction with respect to the plane of the substrate, of the FePt (A-D samples) and the Ag/FePt (E-H samples) nanoparticles. The FePt specimens with $f_{\mathrm{FePt}} \sim 3.5 \mathrm{~nm}$ are ferromagnetic [Figs. 7(a) and 7(b)], with a coercivity $H_{c}$ that increases from 1.9 to $7.8 \mathrm{kOe}$ after thermal annealing, as a consequence of the postannealing structural ordering discussed above. Conversely, the as-deposited FePt nanoparticles with $f_{\mathrm{FePt}} \sim 1.8 \mathrm{~nm}$ (C samples) are superparamagnetic [Fig. 7(c)], confirmed by the fit of the experimental data with the Langevin curve. This is consistent with their disordered crystallographic structure (Fig. 4) and with the fact that their $D_{p}$ is smaller than the superparamagnetic critical size ( $\sim 9 \mathrm{~nm}$ for $A 1 \mathrm{FePt}$ nanoparticles). After annealing, the nanoparticles become ferromagnetic [Fig. 7(d)]. Although the XRD patterns of the specimens with $f_{\mathrm{FePt}}$ $\sim 1.8 \mathrm{~nm}$ show no significant structural transition in the $L 1_{0}$ ordered phase after annealing (Fig. 5), the hour-glass shape of the magnetization curve of the annealed nanoparticles (D samples) suggests the coexistence of nanoislands with the $A 1$

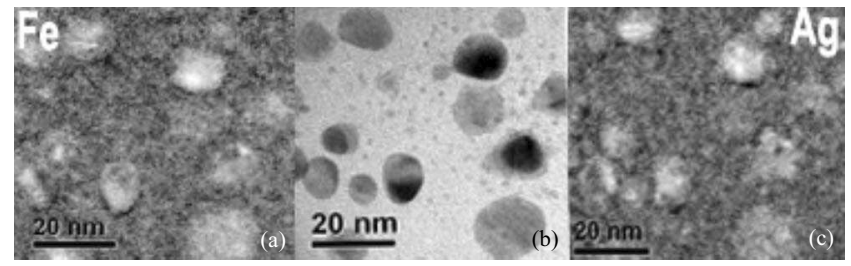

FIG. 6. (a) In-plane bright field TEM image and the EFTEM elemental maps from the same area indicating the presence for $\mathrm{Ag}(\mathrm{b})$ and $\mathrm{Fe}(\mathrm{c})$. 


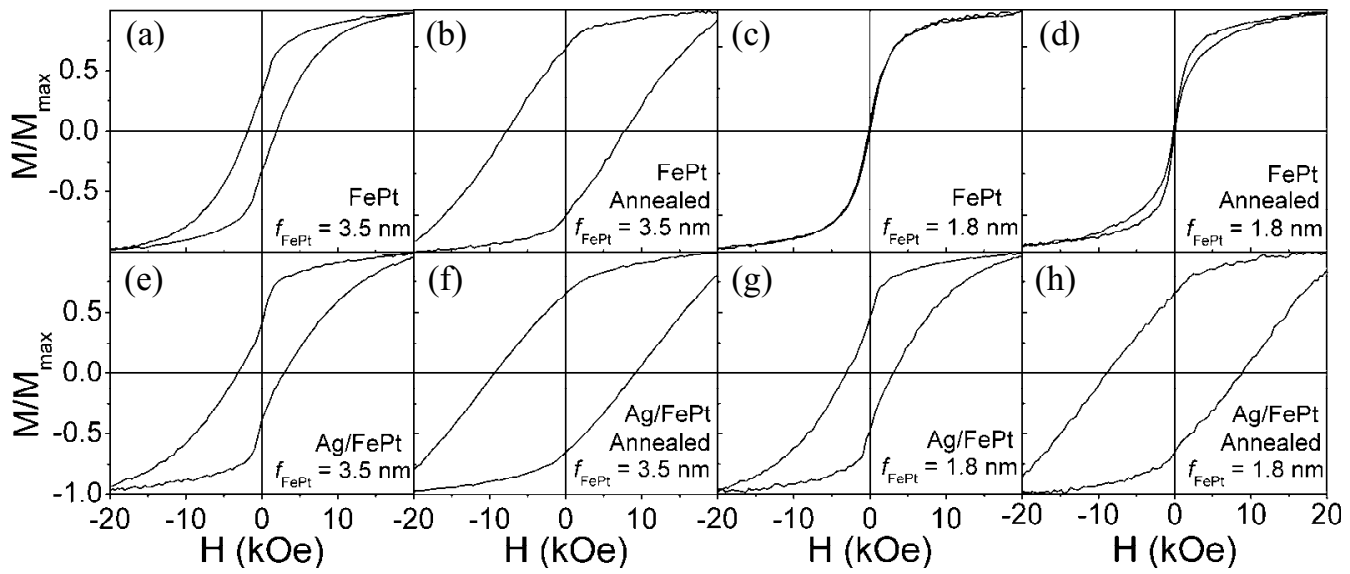

FIG. 7. Magnetization curves measured along the perpendicular direction with respect to the plane of the substrate for (a) A samples, (b) B samples, (c) C samples, (d) D samples, (e) E samples, (f) F samples, (g) G samples, and (h) H samples.

and $L 1_{0}$ crystallographic structures. Figures $7(\mathrm{e})-7(\mathrm{~h})$ show the magnetization curves for the $\mathrm{Ag} / \mathrm{FePt}$ nanoparticles. As can be seen, the use of Ag seeds results in a significant ferromagnetic hardening of the samples, with the maximum $H_{c}=9.4 \mathrm{kOe}$ obtained for the annealed nanoparticles with $f_{\mathrm{FePt}} \sim 3.5 \mathrm{~nm}$ (F samples). Another remarkable result concerns the $\mathrm{Ag} / \mathrm{FePt}$ nanoparticles with $f_{\mathrm{FePt}} \sim 1.8 \mathrm{~nm}$ [Figs. $7(\mathrm{~g})$ and $7(\mathrm{~h})]$. While the as-deposited and the annealed FePt particles are superparamagnetic and ferromagnetically soft, respectively, [Figs. 7(c) and 7(d)], a simple predeposition of Ag clusters results in the significant magnetic hardening of the final nanoislands. These results show that the Ag seeds can be used to favor the $A 1 / L 1_{0}$ transition successfully, promoting a significant magnetic hardening of the deposited FePt nanoparticles.

\section{CONCLUSIONS}

The present study demonstrates that it is possible to nucleate $\mathrm{FePt}$ nanoparticles on $\mathrm{Ag}$ clusters using thin film deposition techniques and discusses the structural, morphological, and magnetic properties of $\mathrm{FePt}$ and $\mathrm{Ag} / \mathrm{FePt}$ nanoparticles deposited on $\mathrm{SiO}_{2}$. The mean particle size increases with an increase in the total nominal thickness of the samples and the addition of Ag leads to a broadening of the PSD. The formation of the $L 1_{0}$ phase is favored at larger $f_{\mathrm{FePt}}$, by the annealing treatment and by the use of $\mathrm{Ag}$ nanoclusters as nucleation sites for the FePt nanoparticles. All nanoparticles are ferromagnetic, except the FePt samples deposited with $f_{\mathrm{FePt}} \sim 1.8 \mathrm{~nm}$, which are superparamagnetic. The presence of $\mathrm{Ag}$ seeds results in a remarkable coercivity enhancement both for the as-deposited and annealed samples with maximum $H_{c}$ of 8.9 and $9.4 \mathrm{kOe}$ obtained for the $\mathrm{Ag} / \mathrm{FePt}$ nanoparticles with $f_{\mathrm{FePt}} \sim 1.8$ and $3.5 \mathrm{~nm}$, respectively. Our results indicate that it is possible to favor the disorder/order transition and promote a significant ferromagnetic hardening of FePt nanoparticles by using Ag nanoclusters, grown by thin film deposition techniques, as nucleation sites.

\section{ACKNOWLEDGMENTS}

This work has been supported by the DYNAMICS grant under Reference No. HPRN-CT-2002-00289 and by the project ENTER on "Advanced Materials for Microelectronics" of the Greek Ministry of Development and the European Commission.

${ }^{1}$ O. Gutfleisch, J. Lyubina, K.-H. Müller, and L. Schultz, Adv. Eng. Mater. 7, 208 (2005).

${ }^{2}$ M. Lu, H. Gong, T. Song, J. P. Wang, H. W. Zhang, and T. J. Zhou, J. Magn. Magn. Mater. 303, 323 (2006).

${ }^{3}$ H. W. Gu, R. K. Zheng, X. X. Zhang, and B. Xu, J. Am. Chem. Soc. 126, 5664 (2004).

${ }^{4}$ S. Sun, C. B. Murray, D. Weller, L. Folks, and A. Moser, Science 287, 1989 (2000).

${ }^{5} \mathrm{X}$. W. Wu, K. Y. Guslienko, R. W. Chantrell, and D. Weller, Appl. Phys. Lett. 82, 3475 (2003).

${ }^{6}$ H. Kanazawa, G. Lauhoff, and T. Suzuki, J. Appl. Phys. 87, 6143 (2000).

${ }^{7}$ S. S. Kang, J. W. Harrell, and D. E. Nikles, Nano Lett. 2, 1033 (2002).

${ }^{8}$ K. Sato, M. Fujiyoshi, M. Ishimaru, and Y. Hirotsu, Scr. Mater. 48, 921 (2003).

${ }^{9}$ Y. K. Takahashi, T. Koyama, M. Ohnuma, T. Ohkubo, and K. Hono, J. Appl. Phys. 95, 2690 (2004).

${ }^{10}$ K. Barmak, J. Kim, D. C. Berry, K. W. Wierman, E. B. Svedberg, and J. K. Howard, J. Appl. Phys. 95, 7486 (2004).

${ }^{11}$ M. Maret, B. Gilles, I. Guhr, B. Riedlinger, M. Albrecht, G. Schatz, and E. Beaurepaire, Nanotechnology 15, 1590 (2004).

${ }^{12}$ J. W. Harrell, D. E. Nikles, S. S. Kang, X. C. Sun, Z. Jia, S. Shi, J. Lawson, G. B. Thompson, C. Srivastava, and N. V. Seetala, Scr. Mater. 53, 411 (2005).

${ }^{13}$ Y. H. Huang, J. Wan, Y. Zhang, H. L. Wang, G. C. Hadjipanayis, D. Niarchos, and D. Weller, J. Magn. Magn. Mater. 294, 232 (2005).

${ }^{14}$ Y. M. Sung, M. K. Lee, K. E. Kim, and T. G. Kim, Chem. Phys. Lett. 443, 319 (2007).

${ }^{15}$ L. Castaldi, K. Giannakopoulos, A. Travlos, D. Niarchos, S. Boukari, and E. Beaurepaire, Nanotechnology 19, 135702 (2008).

${ }^{16} \mathrm{~S}$. Billinge and I. Levin, Science 316, 561 (2007).

${ }^{17}$ C. T. Campbell, Surf. Sci. Rep. 27, 1 (1997).

${ }^{18}$ A. Lo and R. T. Skodje, J. Chem. Phys. 112, 1966 (2000).

${ }^{19}$ E. A. Brandes, Smithells Metals Reference Book (Butterworths, London, 1983).

${ }^{20}$ K. Sato, W. J. Huang, F. Bohra, S. Sivaramakrishnan, A. P. Tedjasaputra, and J. M. Zuo, Phys. Rev. B 76, 144113 (2007).

${ }^{21}$ F. Baletto and R. Ferrando, Rev. Mod. Phys. 77, 371 (2005).

${ }^{22}$ G. Jeffers, M. A. Dubson, and P. M. Duxbury, J. Appl. Phys. 75, 5016 (1994).

${ }^{23}$ R. F. Egerton, Electron Energy Loss Spectroscopy in the Electron Microscope (Plenum, New York, 1996).

${ }^{24}$ J. H. Crawford, Jr. and L. M. Slifkin, Point Defects in Solids (Plenum, New York, 1972), Vol. 1.

${ }^{25}$ K. Barmak, J. Kim, S. Shell, E. B. Svedberg, and J. K. Howard, Appl. Phys. Lett. 80, 4268 (2002).

${ }^{26}$ D. Xie, M. Wang, and L. Cao, Phys. Status Solidi B 242, R76 (2005). 